\title{
Susceptibility to the novel coronavirus disease (COVID-19) is associated with ABO and Rh blood groups: a case-control study from Afghanistan
}

\author{
Khyber Saify ${ }^{1 *}$, Mohammad Sarwar Alborz ${ }^{2}$ and Mostafa Saadat ${ }^{3 *}$ (D)
}

\begin{abstract}
Background: There are preliminary studies about the association between COVID-19 and ABO phenotypes and the results are controversial. There are only two studies which investigated the association of Rh blood groups in addition to $A B O$ with COVID-19; however, in the statistical analysis $A B O$ and Rh blood groups have been considered separately. Therefore, the present case-control study was performed to determine the association of COVID-19 with ABO blood groups considering the Rh blood groups simultaneously. The study was conducted in Kunduz COVID-19 treatment specific center, Spin-Zar Hospital (Kunduz Province, North East Afghanistan). A total of 301 confirmed COVID-19 cases and 1039 healthy blood donors as control group were included in the study.

Results: The $\mathrm{Rh}^{-}$phenotype strongly increased the risk of COVID-19 (OR $=2.97,95 \% \mathrm{Cl} 1.86-3.89, P<0.001$ ). Although blood group A increased the risk of developing COVID-19, the association did not reach statistical significance. In analysis of the combination phenotypes, the $A^{-}$blood group remarkably increased the risk of COVID-19 (OR $=7.24,95 \% \mathrm{Cl} 3.62-14.4, P<0.001)$. Multivariate analysis revealed that the interaction of $\mathrm{Rh}$ and $\mathrm{ABO}$ is significant $(P<0.013)$.
\end{abstract}

Conclusion: These findings indicate that susceptibility to COVID-19 is strongly associated with $\mathrm{A}^{-}$blood group.

Keywords: COVID-19, Susceptibility, ABO, Rh, Blood groups

\section{Background}

Severe acute respiratory syndrome coronavirus 2 (SARSCoV-2), causing coronavirus disease-2019 (COVID-19), is distributed to almost all countries in the world and until now (1 October 2020), more than 32,469,000 confirmed cases with 1,027,000 death have been reported from all around the world. On 24 February 2020, the first COVID19 case was reported in Afghanistan in Herat Province and in a short time, it spread throughout the country [1].

\footnotetext{
* Correspondence: khyber.saify@mohe.gove.af; khaibar.saify@yahoo.com; saadat@shirazu.ac.ir; msaadat41@yahoo.com

'Department of Biology, College of Education Sciences, Kunduz University,

Kunduz, Afghanistan

${ }^{3}$ Department of Biology, College of Sciences, Shiraz University, Shiraz

71467-13565, Iran

Full list of author information is available at the end of the article
}

As of 1 October 2020, there have been 39,285 COVID-19 cases with 1458 deaths in Afghanistan.

Susceptibility to COVID-19 is a multifactorial trait like other infectious disease. Several genetic elements and environmental factors are involved in its etiology. It should be noted that host and viral genetic variations might be involved in the pathogenesis of the disease [2-4]. There are several ecologic and case-control studies investigated the association between common genetic polymorphisms and susceptibility to COVID-19, as well as its mortality [5-13].

The association of genetic polymorphism in blood groups with susceptibility to some infectious diseases has been well established [14]. Very recently, it has been reported that the prevalence and mortality of COVID-19 is associated with ABO (MIM: 616093) and Rh (MIM: 
111680) blood groups, based on an ecologic study. Countries with higher A phenotype and Rh negative blood group showed higher values of the prevalence and mortality rate [5]. However, studies on the association between COVID-19 and ABO phenotypes are at preliminary stage and the results are controversial [15-28].

There are three studies which investigated the association of $\mathrm{Rh}$ blood groups in addition to $\mathrm{ABO}$ with COVID-19; however, in the statistical analysis, $A B O$ and Rh have been considered separately $[15,23,25]$. Therefore, the present case-control study was performed to determine the association of COVID-19 with ABO blood groups considering the Rh blood groups simultaneously.

\section{Methods}

\section{Participants}

This case-control study was accomplished during August and September 2020 in Kunduz COVID-19 treatment specific center, Spin-Zar Hospital supported by Ministry of Public Health of Afghanistan and JACK organization (Kunduz Province, North East Afghanistan). Afghanistan has a heterogeneous population [29-32]; therefore, we selected the participants (patients and controls) from Muslims living in Kunduz City.

A total of 301 confirmed cases of COVID-19 patients were included in the study. From these 136, 127, and 38 individuals were Pashtuns, Tajiks, and Uzbeks, respectively. A control sample of 1039 healthy blood donors was also included in the study. From these 486, 424, and 126 individuals were Pashtuns, Tajiks, and Uzbeks, respectively. In order to increase the statistical power of the analysis, the data were pooled.

The present study was performed in accordance with the ethical codes of the Declaration of Helsinki and was approved by the ethics committee of our university. The information for case group was obtained by a questionnaire. Oral informed consent was obtained from each participant before the study.

\section{Measurements}

Infection by Covid-19 was confirmed using real-time polymerase chain reaction (RT-PCR) test in the Kunduz COVID-19 treatment specific center, Spin-Zar Hospital. The sample test procedure is as follows setups. At first, nasopharyngeal swabs were collected by Citoswab collection and transport kit (Citotest Labware Manufacturing Co., Ltd.). Total RNA was extracted from nasopharyngeal samples by QIAamp Viral RNA Mini Kit (Cat No. 52906 QIAGEN) according to the manufacturer's instructions. RNA samples were used for RT-PCR by detection Kit DA0931, for 2019 Novel Coronavirus (2019nCoV) RNA (PCR-Fluorescence Probing) Da An Gene Co., Ltd. of Sun Yat-sen University of China, using an Applied Biosystems 7500 Real Time PCR System. The reaction mixture was subjected to initial denaturation at $95{ }^{\circ} \mathrm{C}$ for $15 \mathrm{~min}$, followed by 45 cycles of $95{ }^{\circ} \mathrm{C}$ for $15 \mathrm{~s}$, $55{ }^{\circ} \mathrm{C}$ for $45 \mathrm{~s}$, and $72{ }^{\circ} \mathrm{C}$ for $40 \mathrm{~s}$ set. The case samples compared with the positive and negative $\mathrm{C}_{\mathrm{T}}$ curve according to the manufacturer's instructions.

Blood samples were collected without anti-coagulant by finger prick with sterile lancet and the $\mathrm{ABO}$ and $\mathrm{Rh}$ blood group were determined based on standard method of antigen-antibody agglutination test using anti-sera (anti$\mathrm{A}$, anti-B, and anti-D) kit (CinnaClone II Ltd., Iran).

\section{Statistical analysis}

For the control group, the observed frequencies of the $\mathrm{ABO}$ phenotypes were assessed for Hardy-Weinberg equilibrium (HWE) using the $X^{2}$ statistic [33].

Our approach for analysis of the data consisted of three steps. At first, the frequencies of blood group $\mathrm{O}$ (for $\mathrm{ABO}$ blood groups) and $\mathrm{Rh}^{+}$(for $\mathrm{Rh}$ blood groups) compared separately between cases and controls, using logistic regression analysis. In the logistic model, the blood group $\mathrm{O}$ (for $\mathrm{ABO}$ blood groups) and $\mathrm{Rh}^{+}$(for $\mathrm{Rh}$ blood groups) were considered as reference categories and odds ratios (ORs) and their 95\% confidence intervals (95\% CI) of COVID-19 risk were estimated. The genes encoding the $\mathrm{ABO}$ and $\mathrm{Rh}$ blood groups are located on human chromosomes 1 and 9, respectively [34, 35]. It means that they are independent loci. In the second step, combination phenotypes of $\mathrm{ABO}$ and $\mathrm{Rh}$ blood groups compared between cases and controls. In the analysis, $\mathrm{O}+$ phenotype was used as reference group. Finally, multivariable logistic regression analysis was used to investigate the interaction of $\mathrm{ABO}$ and $\mathrm{Rh}$ phenotypes at the third step. Statistical analysis was performed using the SPSS software (SPSS Inc., Chicago, IL, USA; version 11.5). A $P$ value less than 0.05 was considered as statistically significant.

Sample size which is required for identification a significant difference in phenotypic frequency analysis for an effect size of 0.15 (small-medium effect) with assumptions of $\alpha=0.05, \beta=0.20$, Lambda $=14.88$, and $d f$ = 3 were calculated using the GPOWER (www.psycho. uni-duesseldorf.de/aap/projects/gpower) software (version 3.1.3). A minimum sample of 630 would be sufficient. The present case-control study is more than sufficiently powered with an $n=1337$ to detect a smallmedium effect for comparing the frequency of blood groups between the two groups.

\section{Results}

There was no significant difference between COVID-19 cases and healthy controls for ethnicity of the participants $\left(\chi^{2}=0.28, \mathrm{df}=2, P=0.869\right)$. Therefore, the ethnic groups were pooled. Table 1 shows the frequency distribution of $\mathrm{ABO}$ and $\mathrm{Rh}$ blood groups in COVID-19 
Table 1 Frequency of $\mathrm{ABO}$ and Rh blood groups in control and COVID-19 patient groups

\begin{tabular}{|c|c|c|c|c|c|c|c|c|}
\hline Polymorphisms & Controls (\%) & COVID-19 (\%) & OR & $95 \% \mathrm{Cl}$ & $P$ & $\mathrm{OR}^{\mathrm{a}}$ & $95 \% \mathrm{Cl}$ & $P$ \\
\hline \multicolumn{9}{|l|}{$A B O$} \\
\hline $\mathrm{O}$ & 377 (36.39) & 98 (32.56) & 1.0 & - & - & 1.0 & - & - \\
\hline A & 330 (31.85) & $112(37.21)$ & 1.30 & $0.95-1.77$ & 0.090 & 1.31 & $0.96-1.79$ & 0.086 \\
\hline B & $243(23.46)$ & $61(20.26)$ & 0.96 & $0.67-1.38$ & 0.848 & 0.97 & $0.68-1.40$ & 0.910 \\
\hline$A B$ & $86(8.30)$ & $30(9.97)$ & 1.34 & $0.83-2.15$ & 0.221 & 1.36 & $0.84-2.19$ & 0.204 \\
\hline$A+A B$ & $416(40.15)$ & $142(47.18)$ & 1.31 & $0.98-1.76$ & 0.068 & 1.32 & $0.95-1.77$ & 0.063 \\
\hline \multicolumn{9}{|l|}{$\mathrm{Rh}$} \\
\hline $\mathrm{Rh}^{+}$ & 955 (92.18) & $245(81.40)$ & 1.0 & - & - & 1.0 & - & - \\
\hline $\mathrm{Rh}^{-}$ & 81 (7.82) & $56(18.60)$ & 2.97 & $1.86-3.89$ & $<0.001$ & 2.69 & $1.85-3.91$ & $<0.001$ \\
\hline Total & $1036(100.0)$ & $301(100.0)$ & & & & & & \\
\hline
\end{tabular}

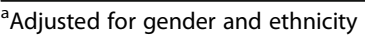

patients and control group. The allelic frequencies of A, $\mathrm{B}$, and $\mathrm{O}$ in control group were $0.2233,0.1707$, and 0.6060 , respectively. The expected values of the $A B O$ phenotypes based on HWE showed high similarity with the observed frequencies $\left(\chi^{2}=0.67, d f=1, P=0.411\right)$. The $\mathrm{Rh}^{-}$blood group compared to the $\mathrm{Rh}^{+}$phenotype strongly increased the risk of COVID-19 $(\mathrm{OR}=2.97$, 95\% CI 1.86-3.89, $P<0.001)$. Although the A phenotype and the $\mathrm{A}+\mathrm{AB}$ blood groups versus to the $\mathrm{O}$ phenotype increased the risk of COVID-19, the association did not reach statistical significance (Table 1 ).

In further analysis, the associations between combination of the $\mathrm{ABO}$ and $\mathrm{Rh}$ phenotypes and susceptibility to COVID-19 were investigated. The results were summarized in Table 2 . The $\mathrm{A}^{-}$vs $\mathrm{O}^{+}$blood group remarkably increased the risk of COVID-19 (OR $=7.24,95 \%$ CI 3.62$14.4, P<0.001)$. The $\mathrm{O}^{-}$vs $\mathrm{O}^{+}$phenotype significantly associated with the risk of COVID-19, which is quite similar with the association between $\mathrm{Rh}^{-}$and susceptibility to COVID-19 (Tables 1 and 2). It seems that Rh and ABO blood groups may have interaction with each other. To investigate this point, multivariable logistic regression analysis was done, using $\mathrm{ABO}$ and $\mathrm{Rh}$ phenotypes as independent variables. Analysis revealed a significant interaction of Rh and ABO blood groups $(P<0.024)$. The same results were obtained after adjustment for ethnicity and gender of the participants (Tables 1 and 2).

\section{Discussion}

There are several studies reporting the relationship of $\mathrm{ABO}$ and $\mathrm{Rh}$ blood groups with susceptibility to COVID-19 or with outcome of the COVID-19 [15-28]. The results are inconsistent. However, it seems that the risk of COVID-19 is positively associated with A blood group compared with $O$ phenotype [17, 18, 24, 26, 28]. Our present finding, confirmed the relationship of $\mathrm{ABO}$ genetic system with susceptibility to COVID-19. Very recently, a genome-wide scan study indicated that human chromosome segment 9q34.2 is associated with severe form of COVID-19 with respiratory failure [36]. It should be mentioned that the ABO locus is located on the 9q34.2 [34]. Taken together, these findings indicate that this locus might be involved in the etiology of the disease.

Table 2 Combination phenotypes of the ABO and Rh blood groups and susceptibility to COVID-19

\begin{tabular}{|c|c|c|c|c|c|c|c|c|c|}
\hline \multicolumn{2}{|c|}{ Polymorphisms } & \multirow[t]{2}{*}{ Controls (\%) } & \multirow[t]{2}{*}{ COVID-19 (\%) } & \multirow[t]{2}{*}{ OR } & \multirow[t]{2}{*}{$95 \% \mathrm{Cl}$} & \multirow[t]{2}{*}{$P$} & \multirow[t]{2}{*}{$O^{a}$} & \multirow[t]{2}{*}{$95 \% \mathrm{Cl}$} & \multirow[t]{2}{*}{$P$} \\
\hline ABO & $\mathrm{Rh}$ & & & & & & & & \\
\hline O & + & 344 (33.20) & $76(25.25)$ & 1.0 & - & - & 1.0 & - & - \\
\hline A & + & 315 (30.41) & 88 (29.24) & 1.26 & $0.89-1.78$ & 0.180 & 1.27 & $0.90-1.80$ & 0.167 \\
\hline B & + & $213(20.56)$ & $53(17.61)$ & 1.12 & $0.76-1.66$ & 0.550 & 1.12 & $0.75-1.66$ & 0.559 \\
\hline$A B$ & + & $83(8.01)$ & $28(9.30)$ & 1.52 & $0.93-2.50$ & 0.094 & 1.54 & $0.93-2.54$ & 0.088 \\
\hline 0 & - & 33 (3.19) & $22(7.31)$ & 3.01 & $1.66-5.46$ & $<0.001$ & 2.97 & $1.63-5.43$ & $<0.001$ \\
\hline A & - & $15(1.45)$ & $24(7.97)$ & 7.24 & $3.62-14.4$ & $<0.001$ & 6.95 & $3.45-13.9$ & $<0.001$ \\
\hline B & - & $30(2.89)$ & $8(2.66)$ & 1.20 & $0.53-2.73$ & 0.652 & 1.29 & $0.56-2.96$ & 0.539 \\
\hline$A B$ & - & $3(0.29)$ & $2(0.66)$ & 3.01 & $0.49-18.3$ & 0.231 & 2.88 & $0.46-17.9$ & 0.257 \\
\hline Total & & 1036 (100.0) & $301(100.0)$ & & & & & & \\
\hline
\end{tabular}

${ }^{\mathrm{a} A d j u s t e d ~ f o r ~ g e n d e r ~ a n d ~ e t h n i c i t y ~}$ 
The novelty of the present study is the strong positive association between $\mathrm{Rh}^{-}$blood group and the risk of developing COVID-19. This finding is consistent with the result of a recently published ecologic study. Based on data, from 86 countries, the authors reported that frequency of the $\mathrm{Rh}^{-}$blood group is positively associated with the prevalence, mortality, and case-fatality of COVID-19. It means that prevalence of COVID-19 is higher in countries where the $\mathrm{Rh}^{-}$blood group is more frequent [5].

COVID-19 is an infectious and communicable disease. Therefore, several factors are involved in the pathogenesis of the disease. In order to confirm the role of the $\mathrm{Rh}$ blood groups on susceptibility to COVID-19, replication of this study in other countries is recommended with respect to these factors.

\section{Conclusions}

The present case-control study indicated that there is a strong positive association between $\mathrm{Rh}^{-}$blood group and the risk of COVID-19. Also, the present study revealed that among the combination phenotypes, the $\mathrm{A}^{-}$blood group is significantly associated with the susceptibility to COVID-19.

\section{Supplementary Information}

The online version contains supplementary material available at https://doi. org/10.1186/s43042-020-00124-x.

\section{Additional file 1}

\section{Abbreviations}

Cl: Confidence interval; COVID-19: Coronavirus disease-2019; HWE: HardyWeinberg equilibrium; OR: Odds ratio; PCR: Polymerase chain reaction; SARSCoV-2: Severe Acute Respiratory Syndrome Coronavirus 2

\section{Acknowledgements}

The authors are indebted to the participants for their close cooperation. The authors would like to gratefully acknowledge the most helpful comments on this paper received from Dr. Maryam Ansari-Lari, Department of Food Hygiene and Public Health, School of Veterinary Medicine, Shiraz University, Shiraz, Iran. This study was supported by Kunduz University (Afghanistan). The authors are grateful for the good cooperation of Dr. Zabihollah Majidi Director of Kunduz COVID-19 treatment specific center, Spin-Zar Hospital and their colleagues.

\section{Authors' contributions}

KS: data collection, methodology, writing original draft of the manuscript; MSA: data collection, methodology; MS: conceptualization, methodology, data analysis, reviewing and editing of the manuscript. All authors have read and approved the manuscript.

\section{Funding}

The authors have not declared a specific grant for this research from any funding agency in the public, commercial or not-for-profit sectors.

\section{Availability of data and materials}

All data generated or analyzed during this study are included in this published article and its supplementary information file.

\section{Ethics approval and consent to participate}

The participants provided their verbal informed consent to be included in the study. The study protocol was approved by the Biology Department
Ethics and Research Committee of the Kunduz University (Afghanistan) registered by the officially protocol (N4-17 2.7.99 on 16 June 2020).

\section{Consent for publication}

None

\section{Competing interests}

The authors declare that they have no competing interests.

\section{Author details}

${ }^{1}$ Department of Biology, College of Education Sciences, Kunduz University, Kunduz, Afghanistan. ${ }^{2}$ Department of Nutrition, College of Medical Sciences Kabul, Abu Ali Ibne-Sina Medical Science University, Kabul, Afghanistan. ${ }^{3}$ Department of Biology, College of Sciences, Shiraz University, Shiraz 71467-13565, Iran.

Received: 7 October 2020 Accepted: 10 December 2020

Published online: 05 January 2021

\section{References}

1. Mousavi SH, Abdi M, Zahid SU, Wardak K (2020) Coronavirus disease 2019 (COVID-19) outbreak in Afghanistan: Measures and challenges. Infect Control Hosp Epidemiol. https://doi.org/10.1017/ice.2020.240

2. Brest $P$, Refae S, Mograbi B, Hofman P, Milano G (2020) Host polymorphisms may impact SARS-CoV-2 infectivity. Trends Genet 36:813-815

3. Di Maria E, Latini A, Borgiani P, Novelli G (2020) Genetic variants of the human host influencing the coronavirus-associated phenotypes (SARS, MERS and COVID-19): rapid systematic review and field synopsis. Hum Genomics 14:30

4. Saini S, Saini A, Thakur CJ, Kumar V, Gupta RD, Sharma JK (2020) Genome-wide computational prediction of miRNAs in severe acute respiratory syndrome coronavirus 2 (SARS-CoV-2) revealed target genes involved in pulmonary vasculature and antiviral innate immunity. Mol Biol Res Commun 9:83-91

5. Ansari-Lari M, Saadat M (2020) The morbidity and mortality of COVID-19 are associated with $\mathrm{ABO}$ and Rh blood groups. Eur J Prev Cardiol: 2047487320939216. https://doi.org/10.1177/2047487320939216

6. Dai X (2020) ABO blood group predisposes to COVID-19 severity and cardiovascular diseases. Eur J Prev Cardiol 27:1436-1437

7. Dai X (2020) C3 polymorphisms represent an important immunological confounder on the spread and outcome of COVID-19. Eur J Prev Cardiol 27: 1333-1334

8. Delanghe JR, De Buyzere ML, Speeckaert MM (2020) C3 and ACE polymorphisms are more important confounders in the spread and outcome of COVID-19 in comparison with ABO polymorphism. Eur J Prev Cardiol 27:1331-1332

9. Delanghe JR, Speeckaert MM, De Buyzere ML (2020) COVID-19 infections are also affected by human ACE1 D/I polymorphism. Clin Chem Lab Med 58: $1125-1126$

10. Kuo CL, Pilling LC, Atkins JL, Masoli JAH, Delgado J, Kuchel GA, Melzer D (2020) APOE e4 genotype predicts severe COVID-19 in the UK Biobank community cohort. J Gerontol A Biol Sci Med Sci:glaa131. https://doi.org/10. 1093/gerona/glaa131

11. Saadat M (2020) An evidence for correlation between the glutathione Stransferase T1 (GSTT1) polymorphism and outcome of COVID-19. Clin Chim Acta 508:213-216

12. Saadat M (2020) No significant correlation between ACE Ins/Del genetic polymorphism and COVID-19 infection. Clin Chem Lab Med 58:1127-1128

13. Saadat M (2020) The morbidity and mortality of COVID-19 are correlated with the Ile105Val glutathione S-transferase P1 polymorphism. Egypt J Med Hum Genet 21:52. https://doi.org/10.1186/s43042-020-00094-0

14. Cooling $L$ (2015) Blood groups in infection and host susceptibility. Clin Microbiol Rev 28:801-870

15. Abdollahi A, Mahmoudi-Aliabadi M, Mehrtash V, Jafarzadeh B, Salehi M (2020) The novel Coronavirus SARS-CoV-2 vulnerability association with ABO/Rh blood types. Iran J Pathol 15:156-160

16. Ad'hiah $\mathrm{AH}$, Allami RH, Mohsin $\mathrm{RH}$, Abdollah MH, Al-Saady AJR, Alsudani MY (2020) Evaluating of the association between $A B O$ blood groups and coronavirus disease 2019 (COVID-19) in Iraqi patients. Egyp J Med Hum Genet 21:50 
17. Fan Q, Zhang W, Li B, Li DJ, Zhang J, Zhao F (2020) Association between ABO blood group system and COVID-19 susceptibility in Wuhan. Front Cell Infect Microbiol 10:404

18. Pourali F, Afshari M, Alizadeh-Navaei R, Javidnia J, Moosazadeh M, Hessami A (2020) Relationship between blood group and risk of infection and death in COVID-19: a live meta-analysis. New Microbes New Infect 37:100743

19. Wu Y, Feng Z, Li P, Yu Q (2020) Relationship between ABO blood group distribution and clinical characteristics in patients with COVID-19. Clin Chim Acta 509:220-223

20. Zalba Marcos S, Antelo ML, Galbete A, Etayo M, Ongay E, García-Erce JA (2020) Infection and thrombosis associated with COVID-19: possible role of the ABO blood group. Med Clin (Barc) 155:340-343

21. Zhao J, Yang Y, Huang H-P et al (2020) Relationship between the ABO blood group and the COVID-19 susceptibility. medRxiv. https://doi.org/10. 1101/2020.03.11.20031096.03.11.20031096

22. Zietz M, Tatonetti NP (2020) Testing the association between blood type and COVID-19 infection, intubation, and death. medRxiv. https://doi.org/10. 1101/2020.04.08.20058073

23. Taha SAH, Osman MEM, Abdoelkarim EAA, Holie MAl, Elbasheir MM, Abuzeid NMK, Al-Thobaiti SA, Fadul SB, Konozy EHE (2020) Individuals with a Rh-positive but not Rh-negative blood group are more vulnerable to SARS-CoV-2 infection: demographics and trend study on COVID-19 cases in Sudan. New Microbes New Infect 38:100763

24. Chegni H, Pakravan N, Saadati M, Ghaffari AD, Shirzad H, Hassan ZM (2020) Is there a link between COVID-19 mortality with genus, age, ABO blood group type, and ACE2 gene polymorphism? Iran J Public Health 49:1582-1584

25. Boudin L, Janvier F, Bylicki O, Dutasta F (2020) ABO blood groups are not associated with risk of acquiring the SARS-CoV-2 infection in young adults. Haematologica:haematol.2020.265066. https://doi.org/10.3324/haematol. 2020.265066

26. Li J, Wang X, Chen J, Cai Y, Deng A, Yang M (2020) Association between ABO blood groups and risk of SARS-CoV-2 pneumonia. Br J Haematol 190: 24-27

27. Zaidi FZ, Zaidi ARZ, Abdullah SM, Zaidi SZA (2020) COVID-19 and the ABO blood group connection. Transfus Apher Sci 102838. https://doi.org/10. 1016/j.transci.2020.102838

28. Gérard C, Maggipinto G, Minon JM (2020) COVID-19 and ABO blood group: another viewpoint. Br J Haematol 190:e93-e94

29. Saify K, Saadat M (2012) Consanguineous marriages in Afghanistan. J Biosoc Sci 44:73-81

30. Saify K, Saadat I, Saadat M (2012) Genetic polymorphisms of glutathione Stransferase T1 (GSTT1) and M1 (GSTM1) in selected populations of Afghanistan. Mol Biol Rep 39:7855-7859

31. Saify K, Saadat I, Saadat M (2013) First survey of the two polymorphisms (Arg194Trp and Arg399GIn) in XRCC1 gene in four Afghanistan populations and comparison with worldwide data. Mol Biol Rep 40:5281-5284

32. Saadat M, Tajbakhsh K (2013) Prevalence of consanguineous marriages in west and south of Afghanistan. J Biosoc Sci 45:799-805

33. Saadat M (2016) Estimation of allelic frequencies for $A B O$ and Rh blood groups. Egypt J Med Hum Genet 16:205-206

34. Ferguson-Smith MA, Aitken DA, Turleau C, de Grouchy J (1976) Localisation of the human ABO: Np-1: AK-1 linkage group by regional assignment of AK1 to 9 q34. Hum Genet 34:35-43

35. Chérif-Zahar B, Mattéi MG, Le Van Kim C, Bailly P, Cartron JP, Colin Y (1991) Localization of the human Rh blood group gene structure to chromosome region 1p34.3-1p36.1 by in situ hybridization. Hum Genet 86:398-400

36. Ellinghaus $D$, Degenhardt $F$, Bujanda L, Buti M, Albillos A, Invernizzi $P$, Fernández J, Prati D, Baselli G, Asselta R et al (2020) Genomewide association study of severe Covid-19 with respiratory failure. N Engl J Med: NEJMoa2020283. https://doi.org/10.1056/NEJMoa2020283

\section{Publisher's Note}

Springer Nature remains neutral with regard to jurisdictional claims in published maps and institutional affiliations.

\section{Submit your manuscript to a SpringerOpen ${ }^{\circ}$ journal and benefit from:}

- Convenient online submission

Rigorous peer review

- Open access: articles freely available online

- High visibility within the field

- Retaining the copyright to your article

Submit your next manuscript at $\boldsymbol{\nabla}$ springeropen.com 